\title{
DFG aiming high with its latest astronomy wants list
}

\section{Bonn}

MAJOR improvements in West Germany's astronomy programme were urged by the Deutsche Forschungsgemeinschaft (DFG), West Germany's basic research funding organization, on 9 July. Structural problems in the universities and insufficient funding are preventing West German students from becoming top-class astronomers and astrophysicists, says a DFG report. The report calls for additional funding of DM771.5 million over the next 15 years to be invested in a variety of new projects as well as a restructuring of West German astronomy.

But the DFG is not backing up its recommendations with money. Instead, it is calling upon both the federal government and the Länder (states) to increase their support of astronomy. The DFG pays out about DM20 million per year for astronomy projects, a figure which it is not planning to increase by more than a few per cent a year.

Recent budget cuts in Länder such as Lower Saxony make it doubtful that all the DFG proposals will be realized. But DFG President Hubert Markl points out that West Germany is "not a poor country" and that temporary problems in some Länder should not divert attention from the goal of a better programme.

University research in astronomy in West Germany is decentralized, having developed around a number of small optical telescopes based at various universities. But significant basic research is now done mainly on large optical telescopes, radio telescopes and other massive pieces of equipment.

West German universities are poor relations compared to the Max Planck Institutes (MPIs). The institutes involved - the MPIs for Astronomy and Nuclear Physics in Heidelberg, for Radioastronomy in Bonn and for Physics and Astronomics in Munich - spend significantly less in administrative costs and are at the same time free to concentrate on research. The potential for further decoupling is a "danger", in the view of Gisbert Winnewisser, director of the physics institute at the University of Cologne.

One of the most urgent problems in West German astronomy is the lack of computer hardware and software for image processing. To remedy this shortage, the DFG recommends that a number of VAX computers be installed in universities, all using international compatible software. Such computers have already been installed in single institutes. The report also urges the formation of a "German Astro-Net" for the exchange of data among universities.
The DFG's other recommendations include a more realistic budget for travel for university professors and students as well as more funds for additional focal plane instruments to be designed at individual universities and used on the various large telescopes accessible to West German researchers.

If the funds can be found, West German astronomers and physicists will embark on a variety of new projects in the next few

$$
\begin{aligned}
& \text { I san't jes anything for that } \\
& \text { dam' butter mountain... }
\end{aligned}
$$

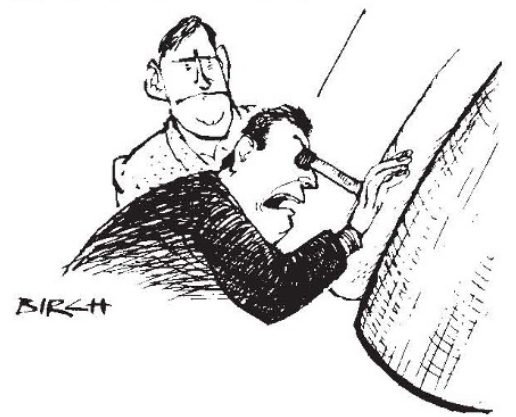

years. Millimetre and submillimetre very long base line interferometry (VLBI) will be supported through the creation of a European VLBI Computation Centre in the Netherlands capable of synthesizing and evaluating data from up to 16 telescopes. West Germany would provide 25 per cent of the estimated DM30 million

cost. If this project is not funded, the DFG recommends the expansion (at a cost of DM 5 million) of the VLBI Correlator at the MPI for Radio-astronomy in Bonn.

A "gravity-wave telescope", will be built, provided that DM60 million is made available for the project. A laser interferometer is planned with two 3-km-long arms. The United States, the United Kingdom and France are interested in carrying out similar projects.

West German researchers are also interested in joining those investigating extra-solar neutrinos. Heinz Völk of the MPI for Nuclear Physics explained proudly that this was a goal even before the discovery of neutrinos from the supernova in the Large Magellanic Cloud. But Völk would not reveal the type of materials that would be used in the proposed detector, which is to be constructed (if funded) in an abandoned coal mine in West Germany.

Once before, in 1962, the DFG issued a similar report on astronomy in West Germany. Its recommendations were for the most part adopted, with highly favourable results. Despite recent stagnation in support for basic research in universities, Markl thinks the chances are good that much of the DM771.5 million programme will be supported by the Ministry for Research and Technology (BMFT). "The BMFT asked us to hurry up and produce the report so that they could consider our recommendations at their next internal meeting", said Markl. "I think we will be able to realize a lot of what we have asked for."

Steven Dickman

\section{Support for basic research under threat}

West Berlin

THE Deutsche Forschungsgemeinschaft (DFG), which funds basic research in West German universities, feels threatened by the budget axe. Its president, Hubert Markl, warned delegates to the organization's annual conference in West Berlin on 7 July that basic research funding may be regarded as an "unnecessary subsidy" by the architects of the forthcoming tax reform.

The DFG budget will rise 3.5 per cent for 1988 , a very small increase in the light of the 12 per cent growth in grant money requested by researchers in the past year. By comparison, the Max Planck Society received a 5 per cent increase for its basic research institutes for fiscal year 1988 .

Markl pointed out that even the 3.5 per cent increase may be frozen, just as were the increases of the past two years. That would make money inaccessible to the DFG until late in 1988 at best.

Markl called attention to the 17 per cent budget increase proposed for the US National Science Foundation (NSF) for 1988, and the longer-term plans to double the NSF budget. He also warned of stronger competition from countries such as Italy and Japan over the next few years.

The pressure on the DFG will be especially severe in the next few years because of a 'bulge' in the West German student population. Some of the same young people who are now crowding universities to 150 per cent capacity will soon be applying for research funding. It would be "economic madness", said Markl, to stop new funding for university research now, after DM50 million has been invested in higher education over the past 25 years.

One new programme, initially supporting five people aged under 33 to the tune of DM200,000 a year for 5 years, is designed to encourage outstanding young researchers and prevent them from leaving academic life.

In his address to the Berlin conference, Markl emphasized the need for the West German government to consider its priorities. The sale of subsidized butter to the Soviet Union alone cost almost as much in 1986 as the DFG budget of DM1,029 million, he said. Steven Dickman 